\title{
Editor's Note: New Developments at JLR
}

\author{
Silas W. Allard \\ Managing Editor
}

Volume thirty-seven brings some notable new developments to the Journal of Law and Religion. First, as our regular readers will recognize, the journal's layout has changed. The new layout will bring benefits to both readers and authors by making our content more discoverable through online searches and better ensuring that all versions of the article-print, PDF, and HTML-are consistent with one another. This new layout is one aspect of JLR's commitment to embracing new developments and opportunities as scholarly publishing evolves. This commitment includes working to expand access to JLR content for all readers. To this end, JLR has participated in Cambridge Core Share ${ }^{1}$ for several years, allowing authors to share read-only versions of their articles and essays with anyone regardless of subscription. In addition, we are excited to report that JLR's open access content continues to grow, and we are excited to be working with Cambridge University Press toward a goal of full open access in the future. ${ }^{2}$

In addition to these technical changes to improve the author and reader experience, we are also excited to offer new content beginning with this volume. In particular, we are drawing on the expertise of our co-editors ${ }^{3}$ to offer regular reflections on the field of law and religion: From where have we come as an interdisciplinary field of study? What are the pressing issues for our field? How can scholars of law and religion expand our interdisciplinary collaborations, as well as enrich and refine the approaches we take in our own work? These are some of the questions upon which our co-editors will reflect in an expanded editorial for each issue and a new, annual state-of-the-field essay. The expanded editorial will appear in each issue and offer reflections from one of our co-editors that seek to provoke new considerations, approaches, or methods among scholars of law and religion. The state-of-the-field essay will appear each January and offer an extend reflection on one of the most pressing or potent issues for the study of law and religion. This issue includes the first offering in each of these genres: M. Christian Green's editorial, "Religion, State, and the Fragility of Democracy," and Mark Movsesian's state-of-the-field essay, "Law, Religion, and the COVID-19 Crisis." Finally, JLR is excited to be exploring how we can collaborate with, and introduce our readers to, colleagues in related fields. Our first collaboration, with the journal Political Theology, will appear in the second issue of this volume (May 2022) and feature essays from scholars of the two fields exchanging source material, methods, and concepts.

We hope you will find these developments intriguing and thought provoking. We value our readers and authors immensely, and we are honored to be a locus for this community of scholars.

\footnotetext{
${ }^{1}$ To read more about Cambridge Share, visit https://www.cambridge.org/core/services/sharing-content.

${ }^{2}$ JLR's open access articles are available at https://www.cambridge.org/core/journals/journal-of-law-and-religion/ open-access, and more information on Cambridge University Press's commitment to open access publishing is available at https://www.cambridge.org/core/services/open-research.

${ }^{3}$ Editorial Board, Journal of Law and Religion, accessed November 15, 2021, https://www.cambridge.org/core/services/ open-research/plan-s.
} 